\title{
The hsp65 gene patterns of less common Mycobacterium and Nocardia spp. by polymerase chain reaction-restriction fragment length polymorphism analysis with capillary electrophoresis
}

\author{
Po-Ling Chang ${ }^{\mathrm{a}}$, Wen-Shyang Hsieh ${ }^{\mathrm{b}}$, Chia-Lien Chiang ${ }^{\mathrm{b}}$, Marion J. Tuohy ${ }^{\mathrm{c}}$, Gerri S. Hall ${ }^{\mathrm{c}}$, \\ Gary W. Procop ${ }^{\mathrm{c}}$, Huan-Tsung Chang ${ }^{\mathrm{a}, \mathrm{d}, *}$, Hsin-Tsung Ho $\mathrm{H}^{\mathrm{b}, \mathrm{e}, *}$ \\ ${ }^{a}$ Department of Chemistry, National Taiwan University, Taipei, Taiwan \\ ${ }^{\mathrm{b}}$ Department of Laboratory Medicine, Mackay Memorial Hospital, Taipei, Taiwan \\ ${ }^{\mathrm{c}}$ Section of Clinical Microbiology, Department of Clinical Pathology, The Cleveland Clinic, Cleveland, OH, USA \\ ${ }^{\mathrm{d}}$ Department of Natural Science Education, National Taitung University, Taitung, Taiwan \\ ${ }^{\mathrm{e}}$ Mackay Medicine, Nursing and Management College, Taipei, Taiwan \\ Received 23 November 2006; accepted 11 February 2007
}

\begin{abstract}
To rapidly identify Mycobacterium and Nocardia spp. without costly probes, we had implemented capillary electrophoresis (CE) in polymerase chain reaction (PCR)-restriction fragment length polymorphism (RFLP) analysis to analyze their 65-kDa heat shock protein (hsp65) gene. The PCR-RFLP analysis with CE (PRACE) involved only one restriction enzyme, HaeIII, and a single electrophoretic separation less than 10 min. Full-range (10-200 bp) RFLP patterns of 12 less common Mycobacterium and 7 Nocardia spp. were investigated. A good agreement was observed between the sizes of restriction fragments resolved by CE and the real sizes deduced from sequence analysis. Including hsp65 gene patterns of 12 Mycobacterium spp. published earlier, differentiation was distinct among 24 Mycobacterium and 7 Nocardia spp. Some closely related species exhibiting similar biochemical characteristics could be well discriminated by an extra HaeIII digestion site. Thus, PRACE offers a nonprobe alternative for rapid identification of various cultured Mycobacterium and Nocardia to the species level.
\end{abstract}

(C) 2007 Elsevier Inc. All rights reserved.

Keywords: Restriction fragment length polymorphism; PCR-RFLP analysis; Capillary electrophoresis; Mycobacteria other than tuberculosis; Nocardia

\section{Introduction}

So far, more than 70 Mycobacterium spp. and at least 12 members of the genus Nocardia have been identified. Opportunistic infections due to mycobacteria other than tuberculosis (MOTT) and Nocardia spp. have been on the rise, predominantly affecting immunocompromised patients. The well-documented species in MOTT infections include Mycobacterium avium complex, Mycobacterium kansasii, Mycobacterium marinum, Mycobacterium scrof-

* Corresponding authors. Huan-Tsung Chang is to be contacted at Department of Chemistry, National Taiwan University, Taipei, Taiwan. Tel.: +886-233661171; fax: +886-233661171. Hsin-Tsung Ho, Department of Laboratory Medicine, Mackay Memorial Hospital, Taipei, Taiwan. Tel.: +886-910014300; fax: +886-225433638.

E-mail addresses: changht@ntu.edu.tw (H.-T. Chang), drho@ms2.mmh.org.tw (H.-T. Ho). ulaceum, Mycobacterium simiae, Mycobacterium szulgai, Mycobacterium ulcerans, Mycobacterium xenopi, and Mycobacterium fortuitum (Falkinham, 1996). Occasionally, infections are attributed to those species that are often encountered as a contaminant in clinical samples, such as Mycobacterium gastri, Mycobacterium gordonae, and Mycobacterium terrae (Wayne and Sramek, 1992). Differentiation of pathogenic and nonpathogenic MOTT from Mycobacterium tuberculosis complex (MTC) has become a relevant diagnostic issue, considering that many MOTT are resistant to the antibiotics used for tuberculosis treatment. Although rapid identification of Mycobacterium spp. is essential for the early diagnosis, the current use of rapid genotypic methods is limited by cost and variety of probes available for MOTT species. Meanwhile, differentiation between Mycobacterium and Nocardia spp. also warrants our greater attention because of their similar staining, 
Table 1

Mycobacterium and Nocardia strains studied for the hsp65 gene patterns by the PCR-RFLP analysis with CE

\begin{tabular}{|c|c|c|}
\hline Organisms & No. of strains & Source of strains ${ }^{\mathrm{a}}$ \\
\hline M. avium Chester & 1 & ATCC 700898 \\
\hline M. celatum & 1 & CCF 56 \\
\hline M. lacticola $^{\mathrm{b}}$ & 1 & CCF 18 \\
\hline M. marinum & 4 & $\begin{array}{l}\text { TMC 927, СCF } 31, \\
\text { CCF } 32, \text { CCF } 33\end{array}$ \\
\hline M. mucogenicum & 3 & CCF 22, CCF 23, CCF 24 \\
\hline M. neoaurum ${ }^{\mathrm{b}}$ & 1 & CCF 19 \\
\hline M. peregrinum & 1 & CCF 57 \\
\hline M. scrofulaceum & 2 & ATCC 19981, CCF 39 \\
\hline M. simiae & 1 & CCF 34 \\
\hline M. terrae & 1 & CCF 40 \\
\hline Mycobacterium triplex & 1 & CCF 35 \\
\hline M. xenopi & 3 & CCF 36, CCF 37, CCF 38 \\
\hline N. abscessus & 1 & CCF 64 \\
\hline Nocardia brasiliensis & 1 & CCF 60 \\
\hline Nocardia cyriacigeorgica & 1 & CCF 61 \\
\hline N. farcinica & 1 & CCF 59 \\
\hline N. nova complex & 1 & CCF 58 \\
\hline N. pseudobrasiliensis & 1 & CCF 63 \\
\hline N. transvalensis complex & 1 & CCF 62 \\
\hline
\end{tabular}

$\mathrm{TMC}=$ Trudeau Mycobacterial Culture Collection.

a The sources of other strains are the culture collection of clinical isolates from the Section of Clinical Microbiology, Cleveland Clinic, Cleveland, $\mathrm{OH}$.

b Two mycobacterial strains (CCF18 and CCF19) were biochemically identified as $M$. lacticola/neoaurum. They were further differentiated as $M$. lacticola (CCF18) and M. neoaurum (CCF19) by DNA sequence analysis.

morphology, colonial, and cultural characteristics (McNeil and Brown, 1994; Olson et al., 1998; Patterson et al., 1992; Short et al., 2005; Staneck et al., 1981). Rapid diagnosis of Mycobacterium and Nocardia infection may allow earlier initiation of effective therapy, thus, improving patient outcome. Therefore, it would be beneficial to develop an accurate, rapid, automatic, and cost-effective method capable of simultaneously distinguishing all species of Mycobacteri$u m$ and Nocardia.

The genotypic approach including probe and nonprobe methods have been used to rapidly identify Mycobacterium spp. for over 10 years. The probe method depends upon genetic amplification and hybridization with labeled probes. The nonprobe method requires the enzymatic digestion of amplified genetic products and electrophoretic separation to obtain the restriction fragment length polymorphism (RFLP) pattern. An algorithm based on the nonprobe method called either polymerase chain reaction (PCR)-restriction enzyme pattern analysis or PCR-RFLP analysis (PRA) has been developed for differentiating mycobacterial species (Brunello et al., 2001; Ringuet et al., 1999; Taylor et al., 1997; Telenti et al., 1993; Wilson et al., 1998). However, there are reasons why both methods cannot be applied to most clinical specimens. For the probe method, such as the Gen-Probe AccuProbes test (Reisner et al., 1994), its identifiable numbers of species are limited and the cost of probes remains high. For the nonprobe method (Brunello et al., 2001; Taylor et al.,
1997), the processes of slab gel electrophoresis are cumbersome and unable to separate the low molecular weight fragments. In recent years, Chang's laboratory team has developed a high-resolution capillary electrophoresis (CE) with laser-induced fluorescence detection to separate DNA fragments in the size range of 11 to $2176 \mathrm{bp}$ in less than 10 min (Chen and Chang, 1999a, 1999b; Hsieh et al., 2000; Huang et al., 2001; Tseng and Chang, 2001; Tseng et al., 2001). Our application of CE in PRA could potentially solve some shortcomings of both methods by offering high-resolution simultaneous screening of all RFLP available species and feasibility of automation. We had improved PRA by implementing CE to analyze the mycobacterial 65-kDa heat shock protein (hsp65) gene. In the previous study (Ho et al., 2004), species-specific hsp65 gene patterns were established from 12 common Mycobacterium spp. As compared with the report of separate runs using 4 enzymes and fluorescence-labeled primers (Hernandez et al., 1999), the CE-based analysis could be achieved at a lower cost using a much smaller loading amount (internal diameter, $75 \mu \mathrm{m}$ ), only one restriction enzyme, and a pair of unlabeled primers. The aim of our current study is to obtain and analyze additional $h s p 65$ gene patterns of 12 less common Mycobacterium and 7 Nocardia spp. collected for the database for identification purpose.

\section{Materials and methods}

\subsection{Study strains}

We examined 20 Mycobacterium strains encompassing 12 species and 7 Nocardia strains from different species (Table 1). Except for one M. scrofulaceum strain from the American Type Culture Collection (ATCC), Rockville, MD, and one M. marinum strain from the Trudeau Mycobacterial Culture Collection, Denver, CO, the source of strains was the culture collection of clinical isolates from the Clinical Microbiology Section, Cleveland Clinic, Cleveland, $\mathrm{OH}$. Identification at the species level was done by classic biochemical tests and further confirmed by DNA sequence analysis with pyrosequencing (Tuohy et al., 2005).

\subsection{DNA preparation, PCR amplification, and RFLP analysis}

Mycobacterial DNA preparation, PCR amplification of hsp 65 gene, and RFLP analysis by CE were performed, according to the methods previously described (Ho et al., 2004).

\section{Results}

A total of 27 strains encompassing 12 Mycobacterium and 7 Nocardia spp. were subjected to the PRA with CE (PRACE). The electrophoregrams of $h s p 65$ gene fragments after HaeIII digestion were obtained for all strains, and 19 
representative ones from each species were shown (Figs. 1 and 2). The fragment sizes of representative strains estimated by $\mathrm{CE}$ and deduced by sequence analysis were also compared (Table 2). Close peaks differing by only 1 or 2 bp can be resolved, such as 23- and 22-bp peaks from
Mycobacterium mucogenicum (Fig. 1E), 19- and 17-bp peaks from M. simiae (Fig. 1I), Nocardia nova complex (Fig. 2E), as well as Nocardia transvalensis complex (Fig. 2G). However, some of them may be overlapped, such as 22- and 21-bp peaks from M. marinum (Fig. 1D),
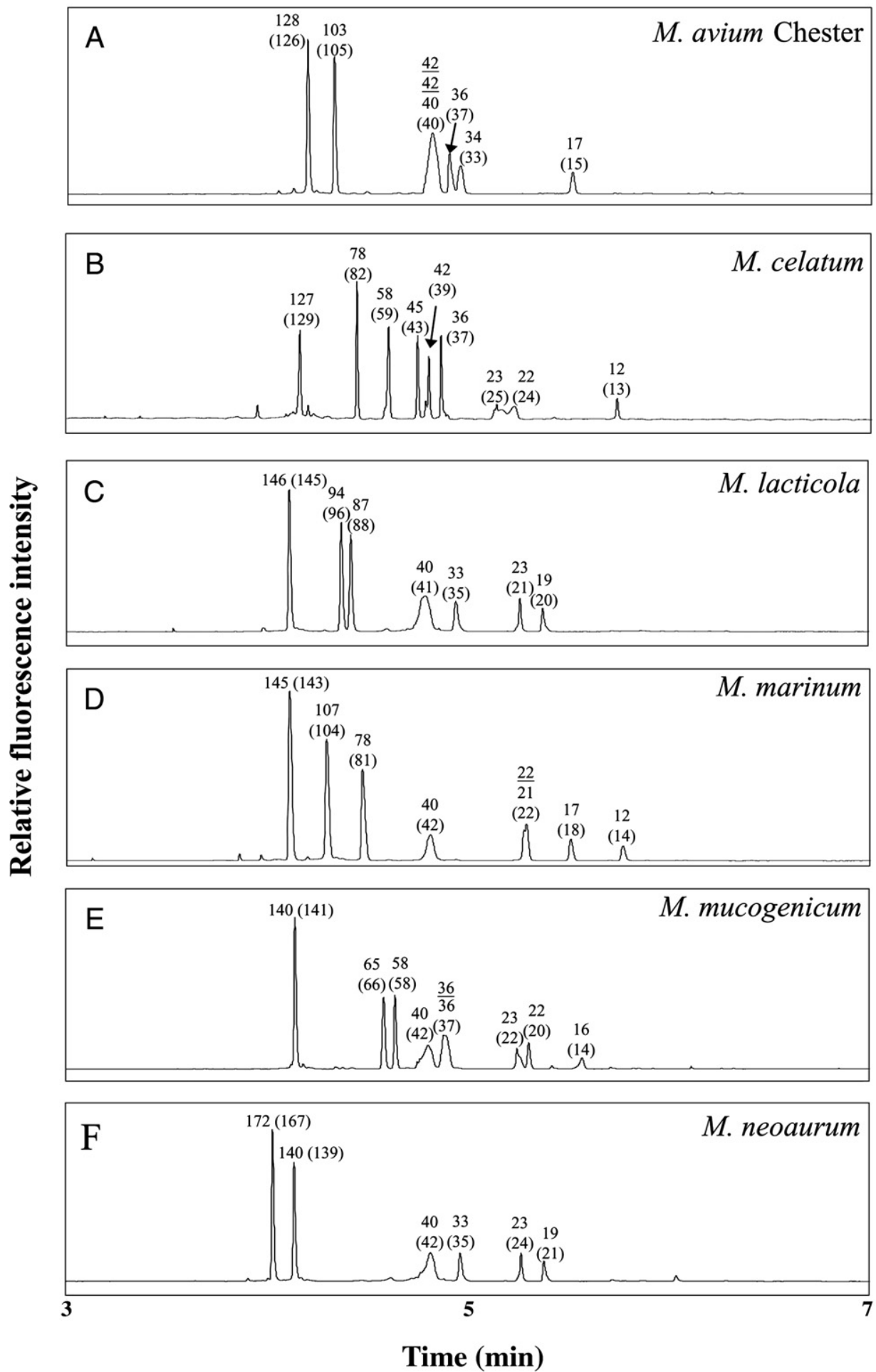

Fig. 1. Electrophoregrams of 12 mycobacterial hsp65 genes with HaeIII digestion. The numbers of base pairs without parentheses represent the real sizes of fragments derived from sequence analysis, whereas those within parentheses were estimated by CE. 
42- and 40-bp peaks from M. avium Chester (Fig. 1A), as well as Nocardia pseudobrasiliensis (Fig. 2F). There are tiny peaks $(<10 \mathrm{bp}$ ) not detected by CE (Table 2$)$, including 6-bp peaks from M. mucogenicum and Mycobacterium neoaurum as well as 9-bp peaks from M. neoaurum and all
7 Nocardia strains. Although our CE could only detect the presence of peaks as small as $12 \mathrm{bp}$ seen in Mycobacterium celatum (Fig. 1B), M. marinum (Fig. 1D), and M. scrofulaceum (Fig. 1H), it provides enough polymorphic patterns necessary for the differentiation of available species. Such
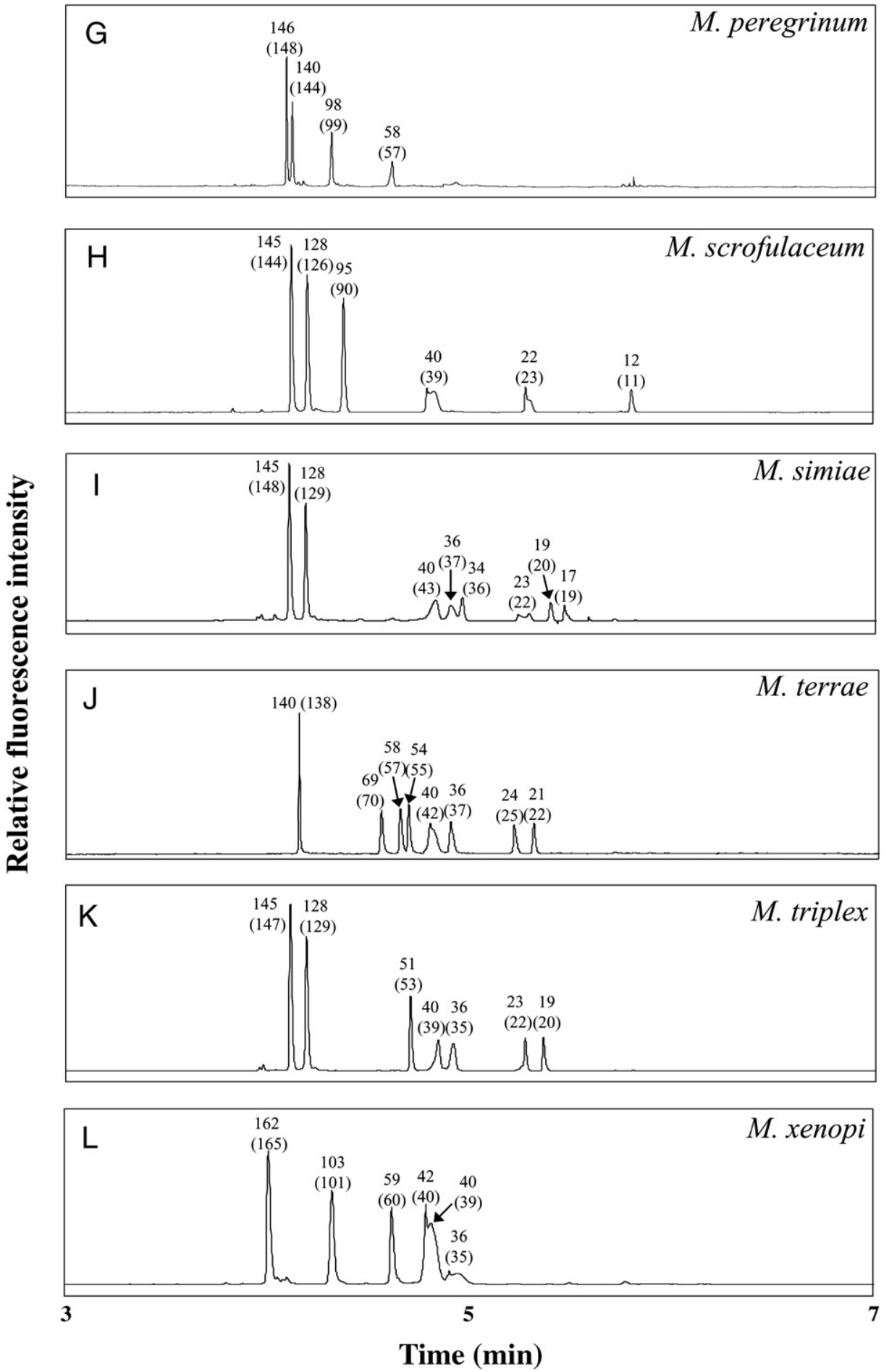

Fig. 1. continued. 

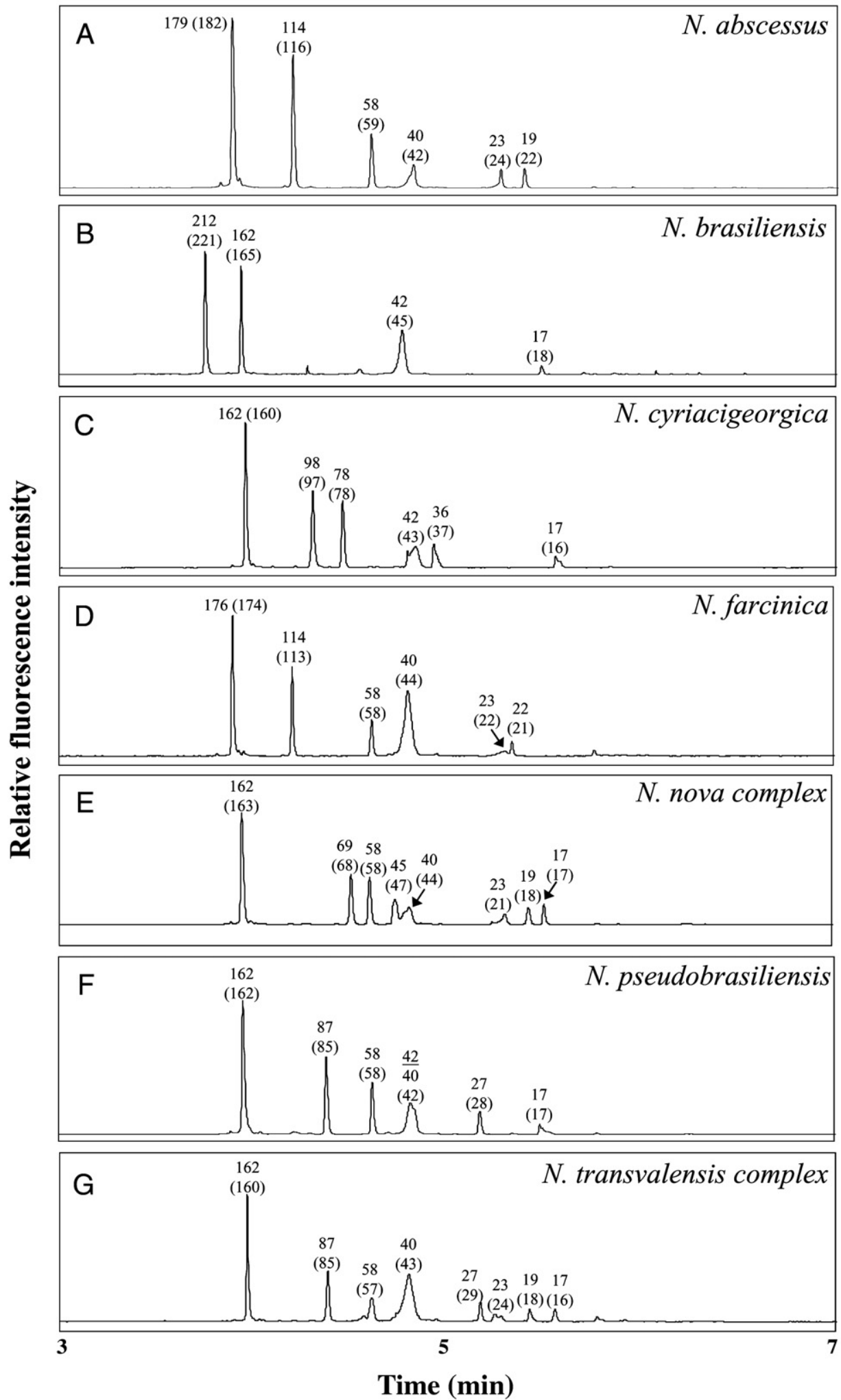

Fig. 2. Electrophoregrams of 7 nocardial hsp65 genes with HaeIII digestion. The numbers of base pairs without parentheses represent the real sizes of fragments derived from sequence analysis, whereas those within parentheses were estimated by CE. 
Table 2

Fragment sizes (bp) of hsp65 genes from 12 Mycobacterium and 7 Nocardia spp. resolved by PRACE in comparison with those deduced from sequence analysis

\begin{tabular}{|c|c|c|c|}
\hline \multirow[t]{2}{*}{ Species (strain) } & \multicolumn{2}{|l|}{ Fragment sizes (bp) as determined by: } & \multirow[t]{2}{*}{ Figure } \\
\hline & Sequence analysis ${ }^{\mathrm{a}}$ & PRACE & \\
\hline M. avium Chester (ATCC 700898) & $128,103,42,42,40,36,34,17$ & $126,105,40^{\mathrm{b}}, 37,33,15$ & Fig. 1A \\
\hline M. celatum (CCF 56) & $127,78,58,45,42,36,23,22,12$ & $129,82,59,43,39,37,25,24,13$ & Fig. 1B \\
\hline M. lacticola (CCF 18) & $\mathbf{1 4 6}, \mathbf{9 4}, \mathbf{8 7}, 40,33,23,19$ & $145,96,88,41,35,21,20$ & Fig. 1C \\
\hline M. marinum (TMC 927) & $145,107,78,40,22,21,17,12$ & $143,104,81,42,22^{\mathrm{b}}, 18,14$ & Fig. 1D \\
\hline M. mucogenicum (CCF 22) & $140,65,58,40,36,36,23,22,16,6^{*}$ & $141,66,58,42,37^{\mathrm{b}}, 22,20,14$ & Fig. 1E \\
\hline M. neoaurum (CCF 19) & $\mathbf{1 7 2}, \mathbf{1 4 0}, 40,33,23,19, \mathbf{9}^{*}, \mathbf{6}^{*}$ & $167,139,42,35,24,21$ & Fig. 1F \\
\hline M. peregrinum (CCF 57) & $146,140,98,58$ & $148,144,99,57$ & Fig. $1 \mathrm{G}$ \\
\hline M. scrofulaceum (ATCC 19981) & $145,128,95,40,22,12$ & $144,126,90,39,23,11$ & Fig. $1 \mathrm{H}$ \\
\hline M. simiae (CCF 34) & $145,128,40,36,34,23,19,17$ & $148,129,43,37,36,22,20,19$ & Fig. 1I \\
\hline M. terrae (CCF 40) & $140,69,58,54,40,36,24,21$ & $138,70,57,55,42,37,25,22$ & Fig. 1J \\
\hline M. triplex (CCF 35) & $145,128,51,40,36,23,19$ & $147,129,53,39,35,22,20$ & Fig. $1 \mathrm{~K}$ \\
\hline M. xenopi (CCF 36) & $162,103,59,42,40,36$ & $165,101,60,40,39,35$ & Fig. 1L \\
\hline N. abscessus (CCF 64) & $179,114,58,40,23,19,9 *$ & $182,116,59,42,24,22$ & Fig. 2A \\
\hline N. brasiliensis (CCF 60) & $212,162,42,17,9^{*}$ & $221,165,45,18$ & Fig. 2B \\
\hline N. cyriacigeorgica (CCF 61) & $162,98,78,42,36,17,9^{*}$ & $160,97,78,43,37,16$ & Fig. 2C \\
\hline N. farcinica (CCF 59) & $176,114,58,40,23,22,9^{*}$ & $174,113,58,44,22,21$ & Fig. 2D \\
\hline N. nova complex (CCF 58) & $162,69,58,45,40,23,19,17,9 *$ & $163,68,58,47,44,21,18,17$ & Fig. 2E \\
\hline N. pseudobrasiliensis (CCF 63) & $162,87,58, \mathbf{4 2}, 40,27,17,9^{*}$ & $162,85,58,42^{\mathrm{b}}, 28,17$ & Fig. 2F \\
\hline N. transvalensis complex (CCF 62) & $162,87,58,40,27, \mathbf{2 3}, \mathbf{1 9}, 17,9^{*}$ & $160,85,57,43,29,24,18,16$ & Fig. 2G \\
\hline
\end{tabular}

a powerful resolution offered a full-range (10-200 bp) RFLP pattern that was not obtainable by the slab gel electrophoresis.

In the PRA of mycobacterial hsp65 gene using 10\% polyacrylamide gel electrophoresis (PAGE), the sizes of restriction fragments generated by HaeIII digestion have been analyzed (Brunello et al., 2001). In that study, the authors concluded that $23(88 \%)$ of the total of 26 fragments generated by HaeIII digestion showed a size differing from the real size by less than $5 \mathrm{bp}$ and $3(12 \%)$ differed from 5 to $10 \mathrm{bp}$. In our study (Table 2), among the total of 76 fragments equal to or larger than $40 \mathrm{bp}$ separated by $\mathrm{CE}$, $73(96 \%)$ differed by less than 5 bp and $3(4 \%)$ differed from 5 to $10 \mathrm{bp}$. Among the total of 50 fragments smaller than 40 bp separated by CE, 49 (98\%) differed by less than 3 bp and $1(2 \%)$ differed by $3 \mathrm{bp}$. Although the strains used for comparison were different between 2 studies, the estimates by $\mathrm{CE}$ were more precise and offered resolution for low molecular weight fragments $(<40 \mathrm{bp})$, which were unavailable by $10 \%$ PAGE.

Because short DNA fragments intercalated with less amounts of fluorescent dye molecules, they fluoresce weakly. Similar concerns about the reproducibility of minor fragments with relative SD (RSD) had been studied and emphasized in the previous report (Chen and Chang, 1999a). In the current study, the electrophoretic peak patterns for each sample are also quite reproducible with the RSD (5 runs) of migration times and peak heights less than $2.0 \%$ and $2.5 \%$, respectively. In addition, the mean size and SD of all fragments estimated by CE were analyzed for 3 species, each containing 3 to 4 strains (Table 3). For the estimated mean sizes in comparison with the corresponding real sizes of 22 fragments, all (100\%) fragments differed by

Table 3

Mean and SD of hsp65 gene fragment sizes (bp) from the strains of 3 Mycobacterium spp. detected by PRACE in comparison with those deduced from the sequence analysis

\begin{tabular}{|c|c|c|c|c|c|c|}
\hline \multirow{2}{*}{$\frac{\text { Species (no. of strains) }}{\text { Method of determination }}$} & \multicolumn{2}{|l|}{ M. marinum (4) } & \multicolumn{2}{|l|}{ M. mисовеnicum (3) } & \multicolumn{2}{|l|}{ M. xenopi (3) } \\
\hline & Sequence analysis ${ }^{\mathrm{a}}$ & PRACE $^{\mathrm{b}}$ & Sequence analysis ${ }^{\mathrm{a}}$ & PRACE $^{\mathrm{b}}$ & Sequence analysis ${ }^{\mathrm{a}}$ & PRACE $^{\mathrm{b}}$ \\
\hline \multirow[t]{8}{*}{ Fragment sizes (bp) } & 145 & $143 \pm 4$ & 140 & $141 \pm 3$ & 162 & $165 \pm 4$ \\
\hline & 107 & $104 \pm 4$ & 65 & $66 \pm 2$ & 103 & $101 \pm 2$ \\
\hline & 78 & $81 \pm 2$ & 58 & $58 \pm 2$ & 59 & $60 \pm 2$ \\
\hline & 40 & $42 \pm 2$ & 40 & $42 \pm 2$ & 42 & $40 \pm 2$ \\
\hline & 22 & $23 \pm 2$ & 36 & $37 \pm 1$ & 40 & $39 \pm 1$ \\
\hline & 21 & $22 \pm 1$ & 23 & $22 \pm 1$ & 36 & $35 \pm 1$ \\
\hline & 17 & $18 \pm 1$ & 22 & $20 \pm 2$ & & \\
\hline & 12 & $14 \pm 2$ & 16 & $14 \pm 2$ & & \\
\hline
\end{tabular}

\footnotetext{
${ }^{\mathrm{a}}$ Values are true sizes of fragments.

b Values are means \pm SDs.
} 
3 bp or less. In terms of the SD, $19(86 \%)$ fragments yielded a reproducible pattern with the variations of $3 \mathrm{bp}$ or less, whereas those of $3(14 \%)$ fragments were equal to $4 \mathrm{bp}$. In a practical sense, the image analysis for differentiating the RFLP patterns could be programmed to accept such a variation in fragment sizes within these limits.

Interestingly enough, 2 pairs of closely related species exhibiting similar biochemical characteristics were found to be clearly distinguished by different HaeIII digestion sites (Table 2). The first pair, Mycobacterium lacticola and M. neoaurum, had fragments 40,33, 23, and $19 \mathrm{bp}$ in common. The fragments in difference were 146, 94, and $87 \mathrm{bp}$ in M. lacticola, and 172, 140, 9, and $6 \mathrm{bp}$ in $M$. neoaurum, as indicated by the bold numbers. Such difference was considered as the results of a different HaeIII digestion site within the precursory 181-bp fragment of both species and an extra HaeIII digestion site within the precursory 146-bp fragment of $M$. neoaurum. The second pair, N. pseudobrasiliensis and N. transvalensis complex, had $162,87,58,40,27,17$, and 9 bp in common. The fragments in difference were $42 \mathrm{bp}$ in $N$. pseudobrasiliensis and 23 and $19 \mathrm{bp}$ in $N$. transvalensis complex, as indicated by the bold numbers. Such a difference was considered as the result of an additional HaeIII digestion site within the 42-bp fragment of $N$. transvalensis complex as compared with $N$. pseudobrasiliensis. The given observations were confirmed by the position of HaeIII digestion in fragment and sequence analysis. Thus, closely related species with similar $h s p 65$ gene sequences could be well differentiated by the electrophoregram because of the presence of a different or extra HaeIII digestion site.

\section{Discussion}

The use of PRA has been the recent focus for recognition of individual mycobacterial and nocardial species (Hernandez et al., 1999; Laurent et al., 1999; Steingrube et al., 1997; Taylor et al., 1997; Telenti et al., 1993; Wilson et al., 1998) as well as separation of mycobacteria from nocardiae (Lungu et al., 1994). We selected the $h s p 65$ gene for our CE-based PRA because its sequence has more variability than the $16 \mathrm{~S}$ rRNA gene and could be exploited to identify both slowly and rapidly growing mycobacteria (RGM) as well as nocardiae (McNabb et al., 2004; Plikaytis et al., 1992; Ringuet et al., 1999; Steingrube et al., 1995b; Wayne and Sramek, 1992). An algorithm based on this approach has been developed for mycobacterial differentiation up to 54 species (Brunello et al., 2001). Following the previous study (Ho et al., 2004), we applied high-resolution CE in the PRA to establish the species-specific RFLP patterns of nocardiae and more mycobacteria. The advantages of high-resolution $\mathrm{CE}$ include the more precise estimates of DNA fragment sizes and the available profile of low molecular weight fragments with detection limit reaching $12 \mathrm{bp}$. As compared with the real sizes deduced from the restriction sites of sequence analysis, $94 \%$ of 40 bp or larger fragments differed by less than 5 bp and $98 \%$ of fragments smaller than 40 bp differed by less than $3 \mathrm{bp}$. A reproducible pattern with SDs of all fragments less than $5 \mathrm{bp}$ was also essential for the RFLP analysis. It appears more convenient to adopt the electrophoregram rather than perform the cumbersome slab gel electrophoresis plus diagnostic algorithm for identification. Including the PRA of 12 Mycobacterium spp. published earlier (Ho et al., 2004), the full-range (10200 bp) RFLP patterns of all 24 Mycobacterium and 7 Nocardia spp. were readily differentiated from each other. The RFLP pattern of M. tuberculosis does not coincide or cross-react with any of MOTT species in which M. celatum (Fig. 1B) has been reported to cause false-positive results by the use of probe method (Butler et al., 1994; Somoskovi et al., 2000). Closely related species exhibiting similar biochemical characteristics could also be well discriminated by the variance of one HaeIII digestion site. In good agreement with the hsp65 gene sequencing, PRACE generates direct unambiguous RFLP patterns and can distinguish medically relevant species. Based on the results, PRACE offers an alternative for simultaneous screening of MTC, MOTT, and Nocardia spp.

M. lacticola (Fig. 1C) and M. neoaurum (Fig. 1F) are closely related species with similar $h s p 65$ gene sequences. The clinical presentation of $M$. neoaurum involves infection of indwelling catheters, primarily in immunosuppressed patients (Davison et al., 1988; George and Schlesinger, 1999). Within the RGM, M. lacticola is also an unusual cause of vascular catheter-related bacteremia. Currently, no biochemical data were available on isolates identified as "M. lacticola" (Kiska et al., 2004). Sequence analysis of $16 \mathrm{~S}$ rRNA gene was required to identify both organisms, and they were found to have $99.3 \%$ identity. By the PRA of hsp65 gene, M. neoaurum and M. lacticola demonstrated almost identical RFLP patterns with a slight difference in the size of the lower molecular weight band of Hae III digest. The given genetic similarities are in concord with our results in which both species could be undoubtedly distinguished by PRACE. As recalled from our previous study (Ho et al., 2004), rapidly growing Mycobacterium abscessus and Mycobacterium chelonae differed by 3 bases in the $16 \mathrm{~S}$ rRNA sequence, as well as slow-growing $M$. kansasii and M. gastri with identical 16S rRNA sequence, could also be conspicuously discriminated by PRACE.

M. mucogenicum (Fig. 1E), formerly M. chelonae-like organism (Springer et al., 1995), was occasionally found to cause posttraumatic wound infections and catheter-related sepsis. It has unique $16 \mathrm{~S}$ rRNA gene sequences in comparison with other RGM such as M. chelonae, M. abscessus, M. fortuitum, Mycobacterium peregrinum, and Mycobacterium smegmatis. Although the $16 \mathrm{~S}$ rRNA sequencing is now the reference sequencing method, it does not permit the differentiation of closely related RGM species. The hsp65 gene sequencing was devised for RGM species because it displayed more polymorphism than the 16S rRNA gene sequencing (Ringuet et al., 1999). The PRA of hsp65 gene 
had also been developed to differentiate clinically important species of RGM, but it required 4 separate runs with different restriction enzymes (Steingrube et al., 1995b). We applied high-resolution CE to hsp65 PRA so that the RFLP patterns of M. mucogenicum and M. peregrinum (Fig. $1 \mathrm{G}$ ) in the current study, along with those of other RGM including M. chelonae, M. abscessus, M. fortuitum, and M. smegmatis in the previous study (Ho et al., 2004), could be unmistakably distinguished with each other.

Nocardia spp. are Gram-positive aerobic actinomycetes found worldwide as soil saprophytes. At least 6 species are pathogenic for humans and may enter the body via inhalation or wounds with contaminated dust particles (McNeil and Brown, 1994). They are responsible for several infections including pulmonary, central nervous system, and cutaneous infections. Nocardiosis is diagnosed by isolation and culture identification. However, their colonial characteristics and cellular morphology are variable, and may be misidentified as Mycobacterium (Olson et al., 1998; Patterson et al., 1992; Short et al., 2005; Staneck et al., 1981; Steingrube et al., 1995a). Accurate identification of pathogenic aerobic actinomycetes is particularly important when aminoglycoside-resistant species (Wilson et al., 1997) such as $N$. transvalensis complex (Fig. 2G) and cephalosporin-resistant species (Steingrube et al., 1993; Wallace et al., 1990) such as Nocardia farcinica (Fig. 2D) are involved or when invasive species (Ruimy et al., 1996; Wallace et al., 1995) such as N. pseudobrasiliensis (Fig. 2F) are encountered.

A recent study reassessed the capacity of $\mathrm{PCR}$-restriction enzyme pattern analysis of hsp65 gene to differentiate Nocardia spp. Their results concluded that hsp65 PRA must no longer be used for Nocardia spp. identification because many species had the same restriction pattern (RodriguezNava et al., 2006). We understand that such a conclusion is made without the availability of high-resolution RFLP patterns. The major disadvantages of PRA with slab gel electrophoresis are that sizes of fragments are not accurately estimated and fragments of similar sizes are not well discriminated, which are especially difficult for fragments smaller than $60 \mathrm{bp}$. Some authors have ignored restriction fragments shorter than $60 \mathrm{bp}$ because they may be primer or primer dimer bands (Telenti et al., 1993). Others take into account fragments up to $50 \mathrm{bp}$ (Steingrube et al., 1995b). Thus, interpretation of fragment sizes is sometimes difficult because of the similarity of restriction patterns. Here, high-resolution CE can overcome the disadvantages of slab gel electrophoresis.

On the basis of hsp65 gene homologies from RGM and Nocardia strains, an RFLP analysis of amplified hsp 65 gene was developed to distinguish these 2 genera (Lungu et al., 1994). Because the number of patterns was large and the fragment sizes were difficult to analyze, the profiles obtained were sometimes hard to interpret. Lungu's difficulty in pattern analysis can be attributed to the lack of full-range (10-200 bp) RFLP patterns as shown in Fig. 2. For example, most species of nocardiae have similar large fragments near 162, 114, and $87 \mathrm{bp}$, which are easily confused with fragments 176,98 , and 78 bp by agarose gel electrophoresis. However, precise estimate of DNA fragment sizes and additional profile in the low molecular weight range evidently make their patterns entirely different and recognizable. For N. pseudobrasiliensis (Fig. 2F) and N. transvalensis complex (Fig. 2G), which differ by only 2 small peaks of 23 and $19 \mathrm{bp}$, the identification will be impossible without the help of better resolution and size calibration. With the advantages of high resolution of PRACE in the present and previous studies, discriminations were discrete among all 24 Mycobacterium and 7 Nocardia spp.

The full-range RFLP patterns provided by technical improvement, as shown by the results of our study, could help us beyond the limitation of identifiable numbers of species and the expensive cost of probes. Nevertheless, there are other questions that remain to be explored, such as additional testing of more than 1 to 2 strains per species, the establishment of all available species-specific RFLP patterns, the improvement of detection limit, and automation. The most important issue is the ability of PRACE to identify mycobacteria or nocardiae directly from clinical isolates. In conclusion, we believe that PRACE offers an excellent nonprobe alternative for rapid identification of multiple cultured Mycobacterium and Nocardia to the species level. Although this study just establishes the database for identification purpose, routine application of PRACE for rapidly identifying more microbiologic species without probes might be feasible soon.

\section{Acknowledgments}

The funding from the National Science Council of Taiwan (NSC 95-2113-M-002-026-MY3) and Mackay Memorial Hospital (MMH grants 9339) is gratefully acknowledged. The authors would also like to thank Cleveland Clinic for providing the mycobacterial and nocardial DNA as gift.

\section{References}

Brunello F, Ligozzi M, Cristelli E, Bonora S, Tortoli E, Fontana R (2001) Identification of 54 mycobacterial species by PCR-restriction fragment length polymorphism analysis of the hsp65 gene. J Clin Microbiol 39:2799-2806.

Butler WR, O’Connor SP, Yakrus MA, Gross WM (1994) Cross-reactivity of genetic probe for detection of Mycobacterium tuberculosis with newly described species Mycobacterium celatum. J Clin Microbiol 32:536-538.

Chen H-S, Chang H-T (1999a) Electrophoretic separation of small DNA fragments in the presence of electroosmotic flow using poly(ethylene oxide) solutions. Anal Chem 71:2033-2036.

Chen H-S, Chang H-T (1999b) Stepwise capillary electrophoretic separation of DNA fragments using poly(ethylene oxide) solutions in the presence of electroosmotic flow. J Chromatogr A 853:337-347.

Davison MB, McCormack JG, Blacklock ZM, Dawson DJ, Tilse MH, Crimmins FB (1988) Bacteremia caused by Mycobacterium neoaurum. $J$ Clin Microbiol 26:762-764.

Falkinham III JO (1996) Epidemiology of infection by nontuberculous mycobacteria. Clin Microbiol Rev 9:177-215. 
George SL, Schlesinger LS (1999) Mycobacterium neoaurum - an unusual cause of infection of vascular catheters: case report and review. Clin Infect Dis 28:682-683.

Hernandez SM, Morlock GP, Butler WR, Crawford JT, Cooksey RC (1999) Identification of Mycobacterium species by PCR-restriction fragment length polymorphism analyses using fluorescence capillary electrophoresis. J Clin Microbiol 37:3688-3692.

Ho H-T, Chang P-L, Hung C-C, Chang H-T (2004) Capillary electrophoretic restriction fragment length polymorphism patterns for the mycobacterial hsp65 gene. J Clin Microbiol 42:3525-3531.

Hsieh M-M, Tseng W-L, Chang H-T (2000) On-column preconcentration and separation of DNA fragments using polymer solutions in the presence of electroosmotic flow. Electrophoresis 21:2904-2910.

Huang M-F, Hsu C-E, Tseng W-L, Lin Y-C, Chang H-T (2001) Separation of dsDNA in the presence of electroosmotic flow under discontinuous conditions. Electrophoresis 22:2281-2290.

Kiska DL, Turenne CY, Dubansky AS, Domachowske JB (2004) First case report of catheter-related bacteremia due to "Mycobacterium lacticola". $J$ Clin Microbiol 42:2855-2857.

Laurent FJ, Provost F, Boiron P (1999) Rapid identification of clinically relevant Nocardia species to genus level by $16 \mathrm{~S}$ rRNA gene PCR. J Clin Microbiol 37:99-102.

Lungu O, Della Latta P, Weitzman I, Silverstein S (1994) Differentiation of Nocardia from rapidly growing Mycobacterium species by PCR-RFLP analysis. Diagn Microbiol Infect Dis 18:13-18.

McNabb A, Eisler D, Adie K, Amos M, Rodrigues M, Stephens G, Black WA, Isaac-Renton J (2004) Assessment of partial sequencing of the 65-kilodalton heat shock protein gene ( $h s p 65$ ) for routine identification of Mycobacterium species isolated from clinical sources. $J$ Clin Microbiol 42:3000-3011.

McNeil MM, Brown JM (1994) The medically important aerobic actinomycetes: epidemiology and microbiology. Clin Microbiol Rev 7:357-417.

Olson ES, Simpson AJ, Norton AJ, Das SS (1998) Not everything acid fast is Mycobacterium tuberculosis - a case report. J Clin Pathol 51:535-536.

Patterson JE, Chapin-Robertson K, Waycott S, Farrel P, McGeer A, McNeil MM, Edberg SC (1992) Pseudoepidemic of Nocardia asteroides associated with a mycobacterial culture system. J Clin Microbiol 30:1357-1360.

Plikaytis BB, Plikaytis BD, Yakrus MA, Butler WR, Woodley CL, Silcox VA, Shinnick TM (1992) Differentiation of slowly growing Mycobacterium species, including Mycobacterium tuberculosis, by gene amplification and restriction fragment length polymorphism analysis. J Clin Microbiol 30:1815-1822.

Reisner BS, Gatson AM, Woods GL (1994) Use of Gen-Probe AccuProbes to identify Mycobacterium avium complex, Mycobacterium tuberculosis complex, Mycobacterium kansasii, and Mycobacterium gordonae directly from BACTEC TB broth cultures. J Clin Microbiol 32:2995-2998.

Ringuet H, Akoua-Koffi C, Honore S, Varnerot A, Vincent V, Berche P, Gaillard JL, Pierre-Audigier C (1999) hsp65 sequencing for identification of rapidly growing mycobacteria. J Clin Microbiol 37:852-857.

Rodriguez-Nava V, Couble A, Devulder G, Flandrois JP, Boiron P, Laurent F (2006) Use of PCR-restriction enzyme pattern analysis and sequencing database for $h s p 65$ gene-based identification of Nocardia species. J Clin Microbiol 44:536-546.

Ruimy R, Riegel P, Carlotti A, Boiron P, Bernardin G, Monteil H, Wallace Jr RJ, Christen R (1996) Nocardia pseudobrasiliensis sp. nov., a new species of Nocardia which groups bacterial strains previously identified as Nocardia brasiliensis and associated with invasive diseases. Int $J$ Syst Bacteriol 46:259-264.

Short WR, Emery C, Bhandary M, O'Donnell JA (2005) Misidentification of Mycobacterium peregrinum, the causal organism of a case of bacteremia and automatic implantable cardioverter defibrillator-associated infection, due to its unusual acid-fast staining characteristics. J Clin Microbiol 43:2015-2017.
Somoskovi A, Hotaling JE, Fitzgerald M, Jonas V, Stasik D, Parsons LM, Salfinger M (2000) False-positive results for Mycobacterium celatum with the AccuProbe Mycobacterium tuberculosis complex assay. J Clin Microbiol 38:2743-2745.

Springer B, Bottger EC, Kirschner P, Wallace Jr RJ (1995) Phylogeny of the Mycobacterium chelonae-like organism based on partial sequencing of the 16S rRNA gene and proposal of Mycobacterium mucogenicum sp. nov.. Int $J$ Syst Bacteriol 45:262-267.

Staneck JL, Frame PT, Altemeier WA, Miller EH (1981) Infection of bone by Mycobacterium fortuitum masquerading as Nocardia asteroides. Am J Clin Pathol 76:216-222.

Steingrube VA, Wallace RJ, Jr., Brown BA, Zhang Y, Steele LC, Young G, Nash DR (1993) Partial characterization of Nocardia farcinica betalactamases. Antimicrob Agents Chemother 37:1850-1855.

Steingrube VA, Brown BA, Gibson JL, Wilson RW, Brown J, Blacklock Z, Jost K, Locke S, Ulrich RF, Wallace Jr RJ (1995a) DNA amplification and restriction endonuclease analysis for differentiation of 12 species and taxa of Nocardia, including recognition of four new taxa within the Nocardia asteroides complex. J Clin Microbiol 33:3096-3101.

Steingrube VA, Gibson JL, Brown BA, Zhang Y, Wilson RW, Rajagopalan M, Wallace Jr RJ (1995b) PCR amplification and restriction endonuclease analysis of a 65 -kilodalton heat shock protein gene sequence for taxonomic separation of rapidly growing mycobacteria. J Clin Microbiol 33:149-153.

Steingrube VA, Wilson RW, Brown BA, Jost KC, Jr., Blacklock Z, Gibson JL, Wallace Jr RJ (1997) Rapid identification of clinically significant species and taxa of aerobic actinomycetes, including Actinomadura, Gordona, Nocardia, Rhodococcus, Streptomyces, and Tsukamurella isolates, by DNA amplification and restriction endonuclease analysis. $J$ Clin Microbiol 35:817-822.

Taylor TB, Patterson C, Hale Y, Safranek WW (1997) Routine use of PCRrestriction fragment length polymorphism analysis for identification of mycobacteria growing in liquid media. J Clin Microbiol 35:79-85.

Telenti A, Marchesi F, Balz M, Bally F, Bottger EC, Bodmer T (1993) Rapid identification of mycobacteria to the species level by polymerase chain reaction and restriction enzyme analysis. $J$ Clin Microbiol 31:175-178.

Tseng W-L, Chang H-T (2001) A new strategy for optimizing sensitivity, speed, and resolution in capillary electrophoretic separation of DNA. Electrophoresis 22:763-770.

Tseng W-L, Hsieh M-M, Wang S-J, Huang C-C, Lin Y-C, Chang P-L, Chang H-T (2001) Analysis of large-volume DNA markers and polymerase chain reaction products by capillary electrophoresis in the presence of electroosmotic flow. J Chromatogr A 927:179-190.

Tuohy MJ, Hall GS, Sholtis M, Procop GW (2005) Pyrosequencing as a tool for the identification of common isolates of Mycobacterium sp. Diagn Microbiol Infect Dis 51:245-250.

Wallace Jr RJ, Tsukamura M, Brown BA, Brown J, Steingrube VA, Zhang YS, Nash DR (1990) Cefotaxime-resistant Nocardia asteroides strains are isolates of the controversial species Nocardia farcinica. J Clin Microbiol 28:2726-2732.

Wallace Jr RJ, Brown BA, Blacklock Z, Ulrich R, Jost K, Brown JM, McNeil MM, Onyi G, Steingrube VA, Gibson J (1995) New Nocardia taxon among isolates of Nocardia brasiliensis associated with invasive disease. J Clin Microbiol 33:1528-1533.

Wayne LG, Sramek HA (1992) Agents of newly recognized or infrequently encountered mycobacterial diseases. Clin Microbiol Rev 5:1-25.

Wilson RW, Steingrube VA, Brown BA, Blacklock Z, Jost Jr KC, McNabb A, Colby WD, Biehle JR, Gibson JL, Wallace Jr RJ (1997) Recognition of a Nocardia transvalensis complex by resistance to aminoglycosides, including amikacin, and PCR-restriction fragment length polymorphism analysis. J Clin Microbiol 35:2235-2242.

Wilson RW, Steingrube VA, Brown BA, Wallace Jr RJ (1998) Clinical application of PCR-restriction enzyme pattern analysis for rapid identification of aerobic actinomycete isolates. $J$ Clin Microbiol $36: 148-152$. 